\title{
Drying Kinetics and Optimisation of Pectin Extraction from Banana Peels via Response Surface Methodology
}

\author{
Chua Bee Lin ${ }^{1, *}$, and Chong Yek Cze ${ }^{1}$ \\ ${ }^{1}$ School of Engineering, Taylor's University, 47500 Subang Jaya, Selangor, Malaysia
}

\begin{abstract}
Banana peels which are the waste in abundance, are used to extract valuable pectin. The gelling ability of the pectin has gained attention in food and pharmaceutical industries. This research aims to select the best drying kinetic model for banana peels and also optimize the pectin extraction process using Box-Behnken response surface design (BBD). Determination of pectin gelling mechanism using degree of esterification (DE) is also focused in this research. In this study, oven drying with temperature $50^{\circ} \mathrm{C}$ was chosen as the best drying temperature due to highest extraction yield. Furthermore, Page-Two-term model was selected as the best model to describe the drying kinetics of banana peels due to highest $\mathrm{R}^{2}$ value $(0.9991)$ and lowest RMSE value $(0.001)$. The optimal extraction conditions given by BBD were $75^{\circ} \mathrm{C}$ extraction temperature, $23 \mathrm{~min}$ extraction time and $1: 33.3 \mathrm{~g} / \mathrm{ml}$ solid-liquid ratio. Likewise, the DE for both pectins extracted using unoptimised and optimised conditions were $71.92 \pm 1.38 \%$ and $76.1 \pm 2.07 \%$ respectively. Both of the pectins were classified as high-methoxyl pectins. The pectin with higher DE also indicated that the rate of gel formation is higher. The results showed that the pectin yield and gelling time has successfully improved after optimised the pectin extraction process.
\end{abstract}

\section{Introduction}

Banana (Musa) is one of the popular food crops that can found in the world market. Banana is generally processed into value-added product such as chips and jam. Because of the high demands of banana products, abundant of banana peels are produced every day and it has reported that about 39000 tons of banana peels are generated annually in U.S [1]. Hence, many scientists tend to find out the application of the banana peels to reduce the industrial waste and a valuable compound, pectin is found in the banana peels [2].

Pectin is a polysaccharide that consists of $\propto-(1,4)$ galacturonic acid [1]. It is widely used as gelling agent for puree and jelly preparation [1]. Pectin is also proved to have wound healing and cholesterol-lowering effects [3]. Pectin is categorized based on the gelling mechanism using degree of esterification (DE) [2]. Pectin can be divided into low-methoxyl $(\mathrm{LM})$ pectin $(\mathrm{DE}<50 \%)$ and high-methoxyl $(\mathrm{HM})$ pectin $(\mathrm{DE}>50 \%)$. LM pectin forms

* Corresponding author: beelin.chua@taylors.edu.my 
gels under divalent ions whereas HM pectin form gels under high sugar concentration solution [4]. Likewise, the gel formation rate of pectin can be determined by DE. Pectin is classified as slow gelling (DE 58-65\%) or fast gelling (DE $>72 \%$ ) [2]. It is important to analyze the esterification degree of pectin because it is used to determine the suitability of end products [2].

Drying is the primary process prior to pectin extraction process. It is normally performed using natural sunlight or artificial dryer such as oven [5]. Drying is used to preserve the quality and extend the shelf life of the foodstuffs by reducing the moisture content to desired level [6]. Sun drying is the conventional method to preserve foodstuffs as it is renewable and low in cost. Yet, large-scale production is not always preferred to use sun drying [7]. Hence, artificial dryer is the alternative to provide uniform and fast drying process. With regards to this, both methods were studied in this research.

Thin-layer drying kinetic models are the mathematical modelling that used to predict the drying behaviour and time of food products [6]. Many popular drying models such as Page, Logarithmic, Henderson and Pabis models have successfully described the drying kinetics of various plants [5], [8,9]. Besides, some new models have developed to improve the accuracy [5], [10]. For instances, a new model which combined the Page and Two-term drying models has proved to give a promising results for cocoa beans [5]. These two models are chosen because both of them give favourable fitting in many applications according to past experience [5]. Yet, this new model, Page-two-term model has only been used in cocoa beans [5]. Regarding to this, this model was performed in this research to study the potential of this new model applies on banana peels and also compared with the Page and Two-term models.

Extraction of pectin can be achieved using acid, ultrasound-assisted (UAE) and microwave-assisted extraction (MAE) [11]. However, UAE which used the acoustic energy to break the cell wall, has gained a lot of attention these years [12]. This is because UAE reduces the extraction time and increases the extraction yield with lower energy consumption [12]. With this respect, UAE was selected to extract the pectin from banana peels in this research.

To the best of author's knowledge, no research has been conducted to study both drying kinetics and optimisation of pectin extraction from banana peels using RSM together [13, 14]. Hence, the present study is carried out with the objectives as follows:

1. To select the best drying models to describe the drying process of banana peels.

2. To optimise the pectin yield with different extraction parameters (extraction temperature, extraction time and solid-liquid ratio) using Box-Behnken response surface design (BBD).

3. To determine the gelling mechanism of pectin based on degree of esterification using titrimetric method of Food Chemical Codex 1981.

\section{Methodology}

This section discusses about the methods that carried out in this research in order to accomplish the objectives.

\subsection{Pre-treatment of banana peels}

Ripened banana peels were collected from a commercial fruit juice store in Taylor's University, Subang Jaya, Selangor, Malaysia. $100 \mathrm{~g}$ of banana peels were washed with distilled water to remove dirt on the surface before cutting into slices. 


\subsection{Drying of banana peels}

In this research, the oven drying was compared with the conventional method which is sun drying. The drying method that produced the highest pectin yield was selected for modelling. The initial moisture content of the samples was measured using moisture analyser (Model XM50, Precisa Gravimetrics AG, Switzerland) to estimate the bone-dry weight before drying. All the samples were spread evenly in single layer on an aluminium tray to avoid any overlapping.

For sun drying, the samples were dried under the sun from 9 a.m. to 5 p.m. and tempered from 5 p.m. to 9 a.m. until it reached constant weight [6]. Weighing balance (Model TX423L, Shimadzu, Japan) was used to measure the weight of the samples. The surrounding temperature $\left(32^{\circ} \mathrm{C}\right)$, humidity $(79.7 \%)$ and wind velocity $(2.6 \mathrm{~m} / \mathrm{s})$ were measured using HVAC datalogger (Model DO2003, Delta OHM, Italy). For oven drying, The peels were dried in an oven (Model UN75, Memmert, Germany) with different temperature $40^{\circ} \mathrm{C}, 50^{\circ} \mathrm{C}, 60^{\circ} \mathrm{C}$ and $70^{\circ} \mathrm{C}$ until the weight of samples reached constant.

After drying, the dried banana peels were grinded into powder using a grinder (Model BL-1525 BG OEM, China). The powdered peels were kept in polyethylene bag at room temperature for further analysis.

\subsection{Mathematical modeling and statistical analysis}

The optimum drying method and temperature that produced the highest pectin yield was used to study the drying kinetic models. $100 \mathrm{~g}$ of pre-treated banana peels were dried using the optimum drying method/temperature and the weight loss of the banana peels was measured every 5 minutes until constant weight was obtained. The moisture content $(M C)$ and moisture ratio $(M R)$ of banana peels were calculated using Eq. (1) and Eq. (2) [5], [15]

$$
M C \text { (dry basis) }=\frac{w_{i}-w_{d b}}{w_{i}}
$$

where, $w_{i}$ is the initial weight of the sample $(\mathrm{g})$ and $w_{d b}$ is the bone-dry weight $(\mathrm{g})$.

$$
M R=\frac{M-M_{e}}{M_{o}-M_{e}}
$$

where, $M_{o}$ is the initial moisture content, $M$ is the moisture content at time and $M_{\epsilon}$ is the moisture content at equilibrium.

The experimental data were fitted into the three drying kinetic models as shown in Table 1. Microsoft Excel SOLVER 2016 was used for non-linear regression analysis [5]. In non-linear regression analysis, statistical indicators, coefficient of determination $\left(\mathrm{R}^{2}\right)$ and root mean square error (RMSE) were used to determine the fitting goodness [5], [15]. The formula of $\mathrm{R}^{2}$ and $\mathrm{RMSE}$ are as follow.

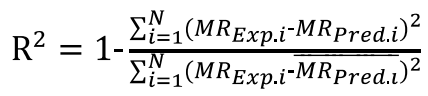

$$
\begin{aligned}
& \mathrm{RMSE}=\sqrt{\frac{1}{N} \sum_{i=1}^{N}\left(M R_{\text {Exp. } i}-M R_{\text {Pred } . i}\right)^{2}}
\end{aligned}
$$

where, $N$ is the data number has run, $M R_{\text {exp }, i}$ and $M R_{\text {pred,i } i}$ are the experimental and predicted moisture ratio value respectively.

Table 1. Drying kinetic models 


\begin{tabular}{|c|c|c|c|}
\hline No. & Model & Equation & Ref. \\
\hline 1 & Page & $M R=e^{-\mathrm{k} t^{\mathrm{n}}}$ & {$[16]$} \\
\hline 2 & Two-term & $M R=\mathrm{a} e^{-\mathrm{k} t}+\mathrm{c} e^{-\mathrm{g} t}$ & {$[5]$} \\
\hline 3 & Page-Two-term & $M R=\mathrm{a} e^{-\mathrm{k} t^{\mathrm{n}}}+\mathrm{c} e^{-\mathrm{g} t^{\mathrm{n}}}$ & {$[5]$} \\
\hline
\end{tabular}

\subsection{Ultrasound-assisted extraction (UAE) of pectin}

The UAE process was conducted based on publication with minor modification $[11,12]$. Four gram of powdered banana peels was added into $0.1 \mathrm{M}$ of citric acid with $\mathrm{pH} 1.5$ and SLR 1:30 $\mathrm{g} / \mathrm{ml}$. The mixture was then placed in the ultrasonic water bath (Elmasonic $\mathrm{P} 120 \mathrm{H}$, Elma, Germany) with temperature $80^{\circ} \mathrm{C}$ and sonicated for $60 \mathrm{~min}$. The power and frequency of sonicator are set to $80 \mathrm{~W}$ and $37 \mathrm{kHz}$ respectively. The mixture was left to cool down and then filtered out using a vacuum filtration. The filtrate was precipitated using $95 \%$ of ethanol with ethanol-to-filtrate ratio $2: 1 \mathrm{v} / \mathrm{v}$. The precipitate and filtrate were then separated using a centrifuge (Scanspeed 1236MG, LaboGene, Denmark) at 6000 RPM for about $30 \mathrm{~min}$. The precipitated pectin was rinsed with $95 \%$ ethanol thrice to remove impurities and then dried in the oven with temperature $50{ }^{\circ} \mathrm{C}$ for 12 hours. The pectin yield based on the total peels used for extraction was calculated using Eq. (5).

$$
\text { Pectin yield }(\%)=\frac{\text { weight of dried pectin }(\mathrm{g})}{\text { initial weight of dried banana peel powder }(\mathrm{g})} \times 100
$$

\subsection{Experimental design using RSM}

Box-Behnken Design (BBD) in Design Expert 7.0 Software was used to optimize the pectin extraction conditions from banana peels. Three independent variables $\left(X_{1}\right.$ : extraction temperature, $X_{2}$ : extraction time and $X_{3}$ : solid-liquid ratio) were employed as these factors were found to be important in affecting the pectin yield based on previous study from publication [17]. For each factor, the level of the factor was chosen by taking the reference from previous work [17]. The three variables with their corresponding coded and actual values is shown in Table 2. By inserting the parameters and levels into BBD, 17 sets of experiment with different extraction conditions were developed as shown in Table 6. The variables in different level combination arranged by the BBD were used for pectin extraction using UAE method as mentioned in Section 2.4.

Table 2. Extraction parameters and levels

\begin{tabular}{|c|c|c|c|c|}
\hline \multirow{2}{*}{ Extraction Parameters } & \multirow{2}{*}{ Code } & \multicolumn{3}{|c|}{ Levels } \\
\cline { 3 - 5 } & & -1 & $\mathbf{0}$ & 1 \\
\hline Extraction temperature $\left({ }^{\circ} \mathrm{C}\right)$ & $X_{1}$ & 60 & 70 & 80 \\
\hline Extraction time (min) & $X_{2}$ & 20 & 40 & 60 \\
\hline Solid-liquid ratio (w/v) & $X_{3}$ & $1: 20$ & $1: 30$ & $1: 40$ \\
\hline
\end{tabular}




\subsection{Statistical analysis and validation of optimal conditions}

Design Expert Statistical 7.0 Software was used to study the experimental data with regression analysis. F-test at P-value (0.05) was used to assess the significance of regression coefficients [7]. The regression model adequacy was evaluated by coefficient of determination, $\mathrm{R}^{2}$ and adjusted $\mathrm{R}^{2}$ [7]. Besides that, the significant independent variables in the model were assessed using ANOVA with confidence level 95\%. Response surface graphs were then generated using the regression coefficients.

The optimum extraction conditions that obtained from BBD were carried out an experiment. Experimental and predicted values were compared to validate the model and error of less than $5 \%$ between both values indicates a good fit [15].

\subsection{Determination of degree of esterification (DE)}

The esterification degree (DE) of the sample was determined using titration method with a little modification from publication of [4]. $2 \mathrm{ml}$ of ethanol was added to $0.2 \mathrm{~g}$ of dried pectin and the mixture was then dissolved in $20 \mathrm{ml}$ of distilled water. The mixture was stirred continuously until the pectin was completely dissolved. 3 drops of phenolphthalein were added to the mixture and $0.1 \mathrm{M}$ of $\mathrm{NaOH}$ was used to titrate the mixture until it turned into pale pink. The titration volume $\left(\mathrm{V}_{1}\right)$ was recorded. Next, the mixture was added with $10 \mathrm{ml}$ of $0.1 \mathrm{M} \mathrm{NaOH}$ and stirred continuously for an hour. $10 \mathrm{ml}$ of $0.1 \mathrm{M} \mathrm{HCl}$ was added and the mixture was shaken until the colour of pale pink disappeared. 3 drops of phenolphthalein were added and $0.1 \mathrm{M} \mathrm{NaOH}$ was used to titrate the mixture until it turned into pale pink. The titration volume $\left(\mathrm{V}_{2}\right)$ is recorded. The experiment was repeated for three times. The DE was calculated using Eq. (6).

$$
\mathrm{DE}(\%)=\frac{V_{1}}{V_{2}+V_{1}} \times 100
$$

\section{Results and discussion}

\subsection{Selection of drying process and drying temperature}

Sun drying (conventional method) and oven drying were compared to select the suitable drying method for banana peels. The drying method was selected based on the highest pectin yield. Since the temperature in the oven can be adjusted, different temperature $\left(40^{\circ} \mathrm{C}, 50^{\circ} \mathrm{C}, 60^{\circ} \mathrm{C}\right.$ and $\left.70^{\circ} \mathrm{C}\right)$ were also tested to select the optimum temperature based on the extraction yield. The pectin yield obtained from sun drying and oven drying was tabulated in the following Table 3 . According to the results, oven drying with temperature of $50^{\circ} \mathrm{C}$ was selected as it gave a highest pectin yield.

Table 3. Pectin yield at different drying process

\begin{tabular}{|c|c|c|}
\hline Method & Temperature $\left({ }^{\circ} \mathbf{C}\right)$ & Pectin Yield (\%) \\
\hline Sun drying & 32 & $1.38 \pm 0.07$ \\
\hline \multirow{2}{*}{ Oven drying } & 40 & $2.84 \pm 0.12$ \\
\cline { 2 - 3 } & 50 & $2.88 \pm 0.07$ \\
\hline
\end{tabular}




\begin{tabular}{|c|c|c|}
\hline \multirow{2}{*}{60} & $1.92 \pm 0.09$ \\
\cline { 2 - 3 } & 70 & $1.78 \pm 0.08$ \\
\hline
\end{tabular}

Sun drying gave the lowest pectin yield $(1.38 \pm 0.07 \%)$ due to rainy season on September 2017. The drying process became less effective as the average daytime temperature was only about $32^{\circ} \mathrm{C}$ with low wind velocity of $2.6 \mathrm{~m} / \mathrm{s}$ and high humidity of $79.7 \%$. These conditions increased the enzymatic degradation since the moisture in the peels could not be removed as soon as possible and this activated the microbiological activity, leading to spoilage of the peels [18]. Thus, the cell structure had destroyed by microbiological activity and this resulted in low pectin yield. The limitation of sun drying is the samples could only dry at day time with sunlight whereas oven drying does not have this limitation. Hence, the samples were able to dehydrate faster than sun drying to prevent microbiological spoilage to produce higher pectin.

For oven drying, results showed that the pectin yield increased from $40^{\circ} \mathrm{C}$ to $50^{\circ} \mathrm{C}$ and started to decrease after $50^{\circ} \mathrm{C}$. Temperature of $50^{\circ} \mathrm{C}$ gave the highest pectin yield $(2.88 \pm 0.07 \%)$ while $70^{\circ} \mathrm{C}$ gave the lowest pectin yield $(1.78 \pm 0.08 \%)$. This could be explained as at low temperature, the heat energy was not strong enough to eliminate the moisture as soon as possible and this led to samples spoilage due to microbiological activity [18]. Yet, high temperature dried and harden the peels surface, blocking the moisture to escape [19]. This is also called as "case hardening" [19]. In other words, high temperature dried the food outside but inside still remained moist. This caused the moisture inside the peels could not be evaporated and the trapped moisture caused bacteria growth and spoilage, resulting in low pectin yield [19].

\subsection{Drying kinetics and modeling}

The initial moisture content of the banana peels before drying was measured as $92.15 \%$. It is normal to have high initial moisture content because most of the fruits contain more than $90 \%$ of water [20]. It is important to measure the initial moisture content because it is used to estimate the bone-dry weight of the sample. The collected moisture content data was converted to moisture ratio and then plotted in graph as shown in Figure 1. Referring to Figure 1, moisture ratio decreased continuously with time and remained constant after 1400 min. The exponential decreasing curve also shows that internal mass transfer had governed by diffusion [15]. The constant zero moisture ratio at the later phase of the process indicated that the moisture of the samples were fully removed. The moisture ratio data was then fitted to the drying models and the following table 4 shows the goodness of fit of each drying model. 


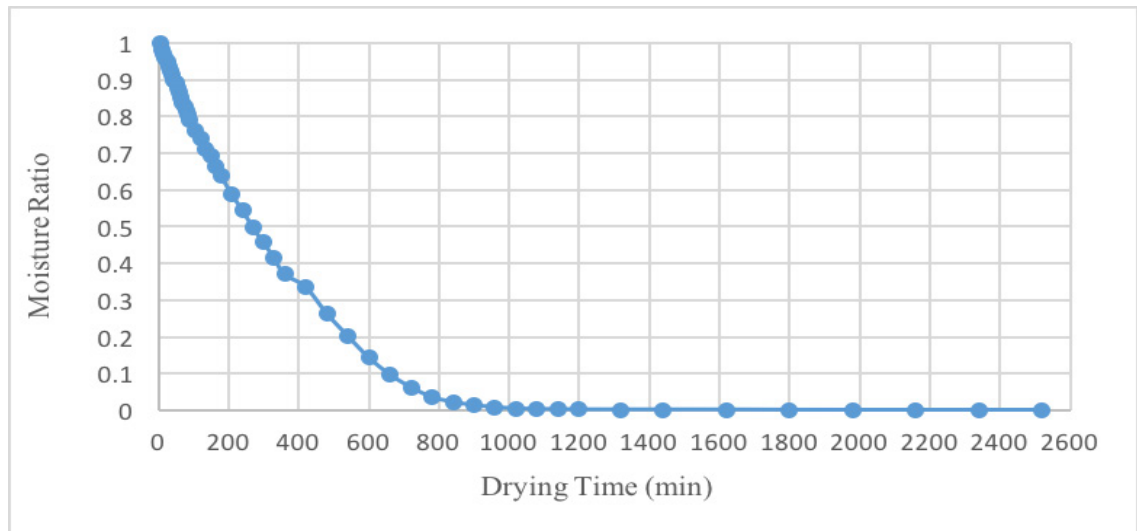

Fig. 1. Graph of moisture ratio against drying time

Table 4. The fitness of different models at $50^{\circ} \mathrm{C}$ drying temperature

\begin{tabular}{|c|c|c|c|c|}
\hline No. & Model name & Coefficients and Constants & $\mathbf{R}^{\mathbf{2}}$ & RMSE \\
\hline 1 & Page & $\mathrm{n}=1.164, \mathrm{k}=0.001098$ & 0.9975 & 0.0026 \\
\hline 2 & Two-term & $\begin{array}{c}\bar{c}=0.0181, \mathrm{k}=1.4819, \\
\mathrm{C}=1.0359, \boldsymbol{\varepsilon}=0.00297\end{array}$ & 0.9947 & 0.0056 \\
\hline 3 & Page-Two-term & $\begin{array}{r}\bar{c}=0.09, \mathrm{k}=0.00405, \mathrm{C}=0.9012, \\
\boldsymbol{\varepsilon}=0.000207, \mathrm{n}=1.4221\end{array}$ & 0.9991 & 0.001 \\
\hline
\end{tabular}

According to Table 4, the fitting goodness of the models according to the statistical indicators ( $\mathrm{R}^{2}$ and RMSE) were in the order of: Page-Two-term $>$ Page $>$ Two-term. Pagetwo-term was selected as the best-fitted drying model to describe the drying process of banana peels as it gave the highest $\mathrm{R}^{2}$ value (0.9991) and lowest RMSE value (0.001). Similar result has been obtained in cocoa beans plant in previous study [5]. Since PageTwo-term model is the new model that specially developed to describe the drying kinetics of cocoa beans, it can be concluded that this new model is also applicable in banana peels according to the satisfactory results.

\subsection{Experimental design and regression analysis}

17 experiments were conducted according to the conditions arranged by BBD as shown in Table 5. The experimental results showed the pectin yield ranging from $2.75 \%$ to $6.03 \%$. Experiment $17\left(X_{1}=70^{\circ} \mathrm{C}, X_{2}=20 \mathrm{~min}\right.$ and $\left.X_{3}=1: 20\right)$ gave the maximum pectin yield $(6.03 \% \pm 0.11 \%)$ whereas experiment $1\left(X_{1}=60^{\circ} \mathrm{C}, X_{2}=40 \mathrm{~min}\right.$ and $\left.X_{3}=1: 20\right)$ gave the minimum pectin yield with only $2.75 \% \pm 0.13 \%$. The influence of extraction parameters on pectin yield was discussed in details in Section 3.4.

Table 5. Box-Behnken design with experimental and predicted pectin yield

\begin{tabular}{|c|c|c|c|c|c|c|}
\hline \multirow{2}{*}{ Std } & \multirow{2}{*}{ Run } & \multirow{2}{*}{$\begin{array}{c}\text { Temp, } X_{1} \\
\left({ }^{\circ} \mathrm{C}\right)\end{array}$} & \multirow{2}{*}{$\begin{array}{c}\text { Time, } X_{2} \\
(\text { min) }\end{array}$} & \multirow{2}{*}{$\underset{(\mathrm{g} / \mathrm{ml})}{\mathrm{SLR}, X_{3}}$} & \multicolumn{2}{|c|}{ Pectin Yield, $Y(\%)$} \\
\hline & & & & & Experimental & Predicted \\
\hline 5 & 1 & 60 & 40 & $1: 20$ & $2.75 \pm 0.13$ & 2.725 \\
\hline
\end{tabular}




\begin{tabular}{|c|c|c|c|c|c|c|}
\hline 1 & 2 & 60 & 20 & $1: 30$ & $4.50 \pm 0.15$ & 4.278 \\
\hline 8 & 3 & 80 & 40 & $1: 40$ & $4.50 \pm 0.10$ & 4.525 \\
\hline 16 & 4 & 70 & 40 & $1: 30$ & $6.00 \pm 0.14$ & 5.540 \\
\hline 12 & 5 & 70 & 60 & $1: 40$ & $3.75 \pm 0.18$ & 3.503 \\
\hline 14 & 6 & 70 & 40 & $1: 30$ & $5.20 \pm 0.09$ & 5.540 \\
\hline 11 & 7 & 70 & 20 & $1: 40$ & $5.75 \pm 0.28$ & 5.804 \\
\hline 3 & 8 & 60 & 60 & $1: 30$ & $3.50 \pm 0.13$ & 3.578 \\
\hline 17 & 9 & 70 & 40 & $1: 30$ & $5.50 \pm 0.08$ & 5.540 \\
\hline 6 & 10 & 80 & 40 & $1: 20$ & $4.85 \pm 0.13$ & 4.682 \\
\hline 7 & 11 & 60 & 40 & $1: 40$ & $3.00 \pm 0.10$ & 3.167 \\
\hline 4 & 12 & 80 & 60 & $1: 30$ & $5.00 \pm 0.22$ & 5.221 \\
\hline 10 & 13 & 70 & 60 & $1: 20$ & $5.00 \pm 0.15$ & 4.946 \\
\hline 13 & 14 & 70 & 40 & $1: 30$ & $5.60 \pm 0.13$ & 5.540 \\
\hline 9 & 15 & 70 & 20 & $1: 20$ & $3.83 \pm 0.15$ & 4.076 \\
\hline 15 & 16 & 70 & 40 & $1: 30$ & $5.40 \pm 0.17$ & 5.540 \\
\hline 2 & 17 & 80 & 20 & $1: 30$ & $6.03 \pm 0.11$ & 5.951 \\
\hline
\end{tabular}

In addition, Table 6 below shows the regression analysis based on the experimental results. ANOVA was used to study the model adequacy and the significant of corresponding variables. Based on rule of thumb, high F-value and p-value lower than 0.05 indicate the model and variable are significant. Referring to the results, quadratic model fitted adequately to the experimental results due to large F-value (19.45) and small p-value (0.004). Likewise, $\mathrm{R}^{2}$ and adjusted $\mathrm{R}^{2}$ are used to check for the model adequacy and suitability. The experimental and predicted values showed a good correlation due to high value of $R^{2}(0.9616)$ and adjusted $R^{2}(0.9121)$ [1]. Besides, adequate precision measures the error related to the predicted response and the desirable value is above 4 [1]. The results showed that the model's adequate precision value was 13.839 which denoted that the model can be used inside the operation region [1].

Likewise, the significant of the corresponding variables on pectin yield $(Y)$ can also be determined by F-value and p-value in Table 6 as shown as below. The higher the F-value and the smaller the p-value, the more significant the variable is. Linear term of extraction temperature $\left(X_{1}\right)$ had the largest effect because of highest F-value and smallest $\mathrm{p}$-value, followed by the quadratic term of extraction temperature $\left(X_{1}{ }^{2}\right)$ and $\operatorname{SLR}\left(X_{3}{ }^{2}\right)$ and the interaction term of $X_{2} X_{3}$ whilst extraction time $\left(X_{2}\right)$ showed the least significant influence 
on the pectin yield. However, the results revealed that linear term of $\operatorname{SLR}\left(X_{3}\right)$, quadratic effect of extraction time $\left(X_{2}{ }^{2}\right)$ and interaction effect of $X_{1} X_{2}$ and $X_{2} X_{3}$ did not have significant effects due to p-values more than 0.05. The following Eq. (7) is the polynomial equation that formulated by the surface model to describe the relationship between the extraction parameters and pectin yield.

$$
\begin{aligned}
& Y(\%)=-55.405+1.24237 X_{1}+0.10112 X_{2}+0.85263 X_{3}-0.0000375 X_{1} X_{2}-0.0015 X_{1} X_{3}- \\
& 0.0039625 X_{2} X_{3}-0.00795 X_{1}^{2}+0.00003125 X_{2}^{2}-0.0097 X_{3}^{2}
\end{aligned}
$$

Referring to Eq. (7), the coefficient with higher value indicates it has higher impact on the response. Linear variables $\left(X_{1}, X_{2}\right.$ and $\left.X_{3}\right)$ and quadratic variable $\left(X_{2}{ }^{2}\right)$ had positive effect on the pectin yield due to positive coefficients in the equation. Positive coefficient indicated the variable was directly proportional to the response value. Oppositely, negative coefficients of interactions $\left(X_{1} X_{2}, X_{1} X_{3}\right.$ and $\left.X_{2} X_{3}\right)$ and quadratic variables $\left(X_{1}{ }^{2}\right.$ and $\left.X_{3}{ }^{2}\right)$ indicated negative effect on the pectin yield. Negative coefficient showed a curvilinear relationship between the variable and response [21]. Curvilinear relationship means the response increases with the variables (negative coefficient) only up to certain point and starts to decrease after that.

Table 6. Variance analysis for quadratic model of response surface

\begin{tabular}{|c|c|c|c|c|c|}
\hline Source & DF & $\begin{array}{c}\text { Sum of } \\
\text { Square }\end{array}$ & $\begin{array}{c}\text { Mean } \\
\text { Square }\end{array}$ & F-value & p-value \\
\hline Model & 9 & 16.18 & 1.80 & 19.45 & 0.0004 \\
\hline$X_{1}$ & 1 & 5.49 & 5.49 & 59.47 & 0.0001 \\
\hline$X_{2}$ & 1 & 1.02 & 1.02 & 11.07 & 0.0126 \\
\hline$X_{3}$ & 1 & 0.041 & 0.041 & 0.44 & 0.5285 \\
\hline$X_{1} X_{2}$ & 1 & $2.25 \times 10^{-4}$ & $2.25 \times 10^{-4}$ & $2.435 \times 10^{-5}$ & 0.9620 \\
\hline$X_{1} X_{3}$ & 1 & 0.090 & 0.090 & 0.97 & 0.3565 \\
\hline$X_{2} X_{3}$ & 1 & 2.51 & 2.51 & 27.19 & 0.0012 \\
\hline$X_{1}{ }^{2}$ & 1 & 2.66 & 2.66 & 28.80 & 0.0010 \\
\hline$X_{2}{ }^{2}$ & 1 & $6.579 \times 10^{-4}$ & $6.579 \times 10^{-4}$ & $7.12110^{-3}$ & 0.9351 \\
\hline$X_{3}{ }^{2}$ & 1 & 3.96 & 3.96 & 42.88 & 0.0003 \\
\hline Residual & 7 & 0.65 & 0.092 & & 0.4412 \\
\hline Lack of Fit & 3 & 0.29 & 0.098 & 1.12 & \\
\hline Pure Error & 4 & 0.35 & 0.088 & & \\
\hline Cor Total & 16 & 16.82 & & & \\
\hline
\end{tabular}




\begin{tabular}{|c|c|c|c|}
\hline Std. Dev. & 0.30 & & \\
\hline Mean & \multicolumn{3}{|c|}{4.72} \\
\hline $\mathrm{R}^{2}$ & 0.9616 \\
\hline Adj- ${ }^{2}$ & 0.9121 \\
\hline $\begin{array}{c}\text { Adeq } \\
\text { Precision }\end{array}$ & 13.839 \\
\hline
\end{tabular}

\subsection{Effect of extraction parameters}

The relationship between the extraction variable was studied with the help of threedimensional (3-D) response surface graphs in Figure 2 and the influence of extraction variables on response was discussed in Section 3.4.1 to 3.4.3.

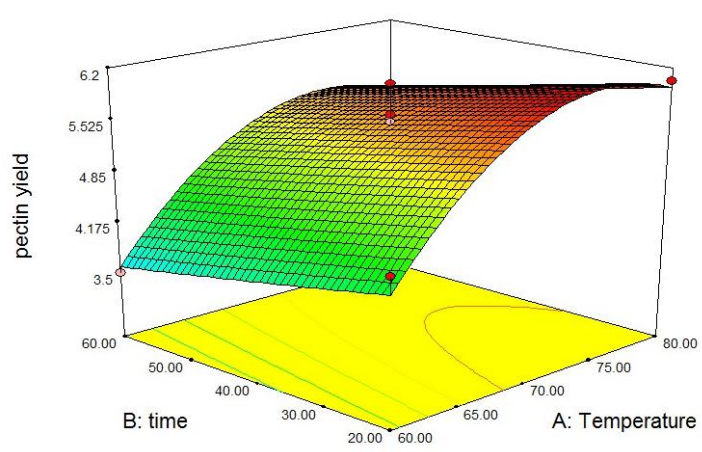

(a)

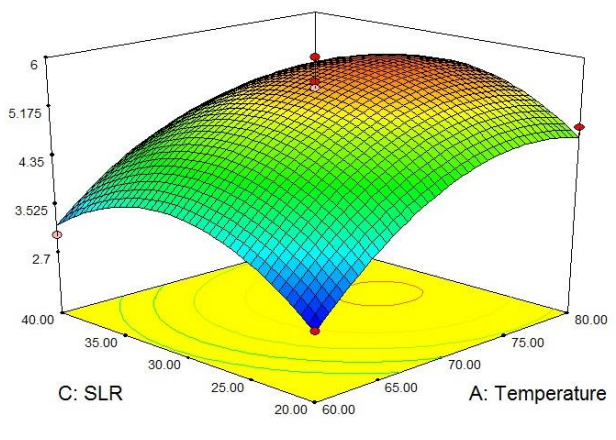

(b)

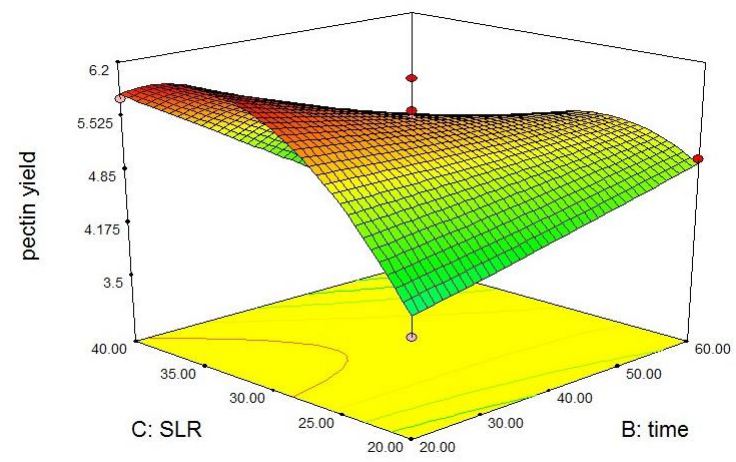

(c) 
Fig. 2. Influence of extraction variables on pectin yield. (a) Time vs temperature at 1:30 g/m SLR. (b) SLR vs temperature at 40 minutes. (c) SLR vs time at $70^{\circ} \mathrm{C}$ temperature.

\subsubsection{Effect of extraction temperature on pectin yield}

Fig. 2 shows that pectin yield increased significantly with temperature. The pectin yield decreased slowly after reaching the temperature of $76^{\circ} \mathrm{C}$. Similar results has been obtained from previous study of [14]. Increasing temperature disrupt the hydrogen bonds and ester linkages, enhancing the solvent penetration to cause higher extraction yield [12]. However, further increasing the temperature decreases the viscosity and surface tension of the extraction solvent [14]. This reduces the cavitation effects and mass transfer intensity, leading to low pectin yield [14]. Moreover, previous study has also reported that high temperature caused thermal degradation of pectin and this resulted in low pectin yield [22].

\subsubsection{Effect of solid to liquid ratio (SLR) on pectin yield}

Pectin yield was found to increase with SLR until approximately 1:30 $\mathrm{g} / \mathrm{ml}$ and further increase the solvent volume results in low extraction yield even though SLR was not the significant influence factor according to ANOVA. Similar trend has been found in previous work of [14]. Other than that, $1: 30 \mathrm{~g} / \mathrm{ml}$ of SLR has also been found to produce maximum pectin yield in previous research of [17]. This can be explained as increasing the volume of extraction solvent enhanced the driving force for mass transfer during extraction, leading to higher pectin released into the surrounding solvent [23]. Yet, excess amount of solvent decreased the pectin yield because the solvent was saturated with the solute and this reduced the penetration and mass transfer rate of the pectin into the extraction solvent [24].

\subsubsection{Effect of extraction time on pectin yield}

Based on the ANOVA results in Table 7 and Fig. 2c, the extraction time and SLR had significant relationship. At low SLR, the pectin yield increased with extraction time whilst the pectin yield decreased with time at high SLR. This can be explained as at low SLR, the driving force is low due to less amount of extraction solvent hence, more reaction time is required for the mass transfer of pectin to the solution [23]. Nonetheless, the pectin yield decreased with longer sonication time at high SLR because the structure of pectin side chain was destructed and decomposed after prolonged exposure of excessive ultrasound waves [22]. Other than that, as mentioned in Section 3.4.2, high SLR saturated the extraction solvent and this reduced the mass transfer between the pectin and the solvent. Therefore, longer extraction time at high SLR resulted in low extraction yield.

\subsection{Determination and validation of optimal extraction conditions}

The optimum extraction conditions (extraction temperature, extraction time and SLR) generated by the Design Expert 7.0 Software were $74.34{ }^{\circ} \mathrm{C}, 22.73 \mathrm{~min}$ and $1: 33.3 \mathrm{~g} / \mathrm{ml}$ respectively with the predicted pectin yield of $6.19 \%$. By considering the operability and limitation of apparatus in real process, the optimal extraction temperature and extraction time were round off to $75^{\circ} \mathrm{C}$ and $23 \mathrm{~min}$ respectively. The suitability of optimized conditions was validated experimentally. The experimental pectin yield obtained was $6.08 \% \pm 0.2 \%$ while the error percentage based on the predicted value was only $1.78 \%$. The small deviation between the experimental and predicted value might due to the decimal place of the extraction conditions value was round off for operability. Using the 
unoptimised conditions, only $5 \%$ of pectin yield was obtained but the yield had successfully improved by $21.66 \%$ after optimisation.

\subsection{Esterification degree of pectin before and after optimisation}

The degree of esterification (DE) of the pectin before and after optimisation were compared to determine the gelling mechanism. The $\mathrm{DE}$ of the pectin before and optimisation were found as $71.92 \% \pm 1.38 \%$ and $76.1 \% \pm 2.07 \%$ respectively. Both of the DE values were acceptable because the tissue pectin is usually in the range of 60 to $90 \%$ [2]. However, the $\mathrm{DE}$ of pectin after optimisation was slightly higher than the pectin before optimisation because of lower temperature was used in optimised conditions. Previous research has reported that $\mathrm{DE}$ values reduced with higher temperature because the methly esterified carboxyl groups that presented in the pectin chains could be destroyed at high temperature [25].

Since both DE values were above $50 \%$, the pectins were classified as high methoxyl (HM) pectins which can form gel with high sugar concentration. In food industry, HM pectin is suitable to process into high sugar jam and canned food [26]. Besides, the pectins were also classified as fast gelling pectins as the DE values were more than $71 \%$ [27]. Since the setting rate increased with DE values, the optimized pectin could form gels faster than the pectin before optimisation due to higher DE value [28]. Based on the results, it can be concluded that, the type of gel formation remained unchanged after optimisation yet the gelling speed had improved.

\section{Conclusion}

In this study, oven drying with $50^{\circ} \mathrm{C}$ was suggested as the optimum drying temperature for banana peels because it provided the highest pectin yield. Among three drying models (Page, Two-term and Page-Two-term), Page-Two-term Model was selected as the most suitable model to describe the drying kinetic of banana peels with $0.9991 \mathrm{R}^{2}$ value and 0.001 RMSE. Three extraction conditions of pectin extraction from banana peels were optimized using Box-Behnken Design and the optimal conditions were $75^{\circ} \mathrm{C}$ of extraction temperature, $23 \mathrm{~min}$ of extraction time and $1: 33.3 \mathrm{~g} / \mathrm{ml}$ of SLR. Using the optimal conditions, the experimental pectin yield was found as $6.08 \pm 0.2 \%$ which was not much different with the predicted yield of $6.19 \%$. After optimised the extraction process, the isolated pectin was still remained as high-methoxyl pectin ( $\mathrm{DE}>50 \%)$ yet the extraction yield and gelling time had successfully improved.

The authors would like to acknowledge Taylor's University Lakeside for providing financial support under TRGS/MFS/1/2016/SOE/004.

\section{References}

1. Swamy, G. J. \& Muthukumarappan, K. Optimization of continuous and intermittent microwave extraction of pectin from banana peels. Food Chem. 220, 108-114 (2017).

2. Castillo-Israel, K. A. T. et al. Extraction and characterization of pectin from Saba banana [Musa 'saba'(Musa acuminata x Musa balbisiana)] peel wastes: A preliminary study. Int. Food Res. J. 22, 202-207 (2015).

3. Freitas de Oliveira, C. et al. Extraction of pectin from passion fruit peel assisted by 
ultrasound. LWT - Food Sci. Technol. 71, 110-115 (2016).

4. Liew, S. Q., Chin, N. L. \& Yusof, Y. A. Extraction and Characterization of Pectin from Passion Fruit Peels. Agric. Agric. Sci. Procedia 2, 231-236 (2014).

5. Hii, C. L., Law, C. L. \& Cloke, M. Modeling using a new thin layer drying model and product quality of cocoa. J. Food Eng. 90, 191-198 (2009).

6. Khawas, P., Das, A. J., Dash, K. K. \& Deka, S. C. Thin-layer drying characteristics of Kachkal banana peel (Musa ABB) of Assam, India. Int. Food Res. J. 21, 975982 (2014).

7. Toĝrul, I. T. \& Pehlivan, D. Modelling of thin layer drying kinetics of some fruits under open-air sun drying process. J. Food Eng. 65, 413-425 (2004).

8. Onwude, D. I., Hashim, N., Janius, R. B., Nawi, N. M. \& Abdan, K. Modeling the Thin-Layer Drying of Fruits and Vegetables: A Review. Compr. Rev. Food Sci. Food Saf. 15, 599-618 (2016).

9. Ertekin, C. \& Firat, M. Z. A comprehensive review of thin-layer drying models used in agricultural products. Crit. Rev. Food Sci. Nutr. 57, 701-717 (2017).

10. Fernando, J. A. K. M. \& Amarasinghe, A. D. U. S. Drying kinetics and mathematical modeling of hot air drying of coconut coir pith. Springerplus 5, 807 (2016).

11. Bagherian, H., Zokaee Ashtiani, F., Fouladitajar, A. \& Mohtashamy, M. Comparisons between conventional, microwave- and ultrasound-assisted methods for extraction of pectin from grapefruit. Chem. Eng. Process. Process Intensif. 50, 1237-1243 (2011).

12. Minjares-Fuentes, R. et al. Ultrasound-assisted extraction of pectins from grape pomace using citric acid: A response surface methodology approach. Carbohydr. Polym. 106, 179-189 (2014).

13. Hii, C. L., Law, C. L. \& Cloke, M. Modelling of Thin Layer Drying Kinetics of Cocoa Beans During Artificial and Natural Drying. J. Food Eng. 3, 1-10 (2008).

14. Moorthy, I. G., Maran, J. P., Surya, S. M., Naganyashree, S. \& Shivamathi, C. S. Response surface optimization of ultrasound assisted extraction of pectin from pomegranate peel. Int. J. Biol. Macromol. 72, 1323-1328 (2015).

15. Kumar, S. k. Drying Kinetics of Banana Peel. J. Food Process. Technol. 6, 10-12 (2015).

16. da Silva, W. P., e Silva, C. M. D. P. S., Gama, F. J. a. \& Gomes, J. P. Mathematical models to describe thin-layer drying and to determine drying rate of whole bananas. J. Saudi Soc. Agric. Sci. 13, 67-74 (2014).

17. KulkarniS.G. \& Vijayanand, P. Effect of extraction conditions on the quality characteristics of pectin from passion fruit peel (Passiflora edulis f. flavicarpa L.). LWT - Food Sci. Technol. 43, 1026-1031 (2010).

18. Manjarres-Pinzon, K., Cortes-Rodriguez, M. \& Rodríguez-Sandoval, E. Effect of drying conditions on the physical properties of impregnated orange peel. Brazilian J. Chem. Eng. 30, 667-676 (2013).

19. Marianski, S. \& Marianski, A. The Art of Making Fermented Sausages. (2009).

20. Food Analysis: Theory and Practice - Yeshajahu Pomeranz, Clifton E. Meloan Google Books.

21. Lee, W. C., Yusof, S., Hamid, N. S. A. \& Baharin, B. S. Optimizing conditions for enzymatic clarification of banana juice using response surface methodology (RSM). J. Food Eng. 73, 55-63 (2006).

22. $\mathrm{Xu}, \mathrm{Y}$. et al. Effects of ultrasound and/or heating on the extraction of pectin from grapefruit peel. J. Food Eng. 126, 72-81 (2014).

23. Chaharbaghi, E., Khodaiyan, F. \& Hosseini, S. S. Optimization of pectin extraction from pistachio green hull as a new source. Carbohydr. Polym. 173, 107-113 
(2017).

24. Prakash Maran, J., Sivakumar, V., Thirugnanasambandham, K. \& Sridhar, R. Optimization of microwave assisted extraction of pectin from orange peel. Carbohydr. Polym. 97, 703-709 (2013).

25. Huang, X., Li, D. \& Wang, L. jun. Characterization of pectin extracted from sugar beet pulp under different drying conditions. J. Food Eng. 211, 1-6 (2017).

26. CP Kelco. GENU® pectin. (A HUBER COMPANY, 2010).

27. Sharma, B. R., Naresh, L., Dhuldhoya, N. C., Merchant, S. U. \& Merchant, U. C. An Overview on Pectins. Times food Process. J. 51, 44-51 (2006).

28. Guidetti, R. et al. Extraction and Characterization of Pectin from Citric Waste. Chem. Eng. Trans. 44, 1-7 (2015). 